\title{
Transforming Energy Instruction in Middle School to Support Integrated Understanding and Future Learning
}

JEFFREY NORDINE

Department of Education, One Trinity Place, Trinity University, San Antonio, TX 78257, USA

JOSEPH KRAJCIK

School of Education, University of Michigan, Ann Arbor, MI 48109, USA

DAVID FORTUS

Department of Science Teaching, Weizmann Institute of Science, Rehovot 76100, Israel

Received 30 December 2009; revised 30 July 2010; accepted 24 August 2010

DOI 10.1002/sce.20423

Published online 9 December 2010 in Wiley Online Library (wileyonlinelibrary.com).

\begin{abstract}
Energy is a fundamental unifying concept of science, yet common approaches to energy instruction in middle school have shown little success with helping students develop their naïve ideas about energy into more sophisticated understandings that are useful for making sense of their experiences. While traditional energy instruction often focuses on simple calculations of energy in idealized systems, we developed a new middle school energy unit that focuses qualitatively on the energy transformations that occur in everyday, nonidealized, systems. In this article, we describe our approach to energy instruction
\end{abstract}

Correspondence to: Jeffrey Nordine; e-mail: jnordine@trinity.edu Contract grant sponsor: National Science Foundation.

Contract grant number. ESI-0227557 (CCMS).

Any opinions, findings, and conclusions or recommendations expressed in this material are those of the authors and do not necessarily reflect the views of the National Science Foundation. 
and report the effects this approach had on students' energy conceptions, ability to perform on distal criterion-referenced assessments, and preparation for future energy-related learning. Results indicate that during instruction, students' energy conceptions progress from a set of disconnected ideas toward an integrated understanding that is organized around the principle of transformation, and that these more integrated conceptions both boost students' ability to make sense of everyday phenomena and lay the groundwork for more efficient and meaningful energy-related learning in the future. (C) 2010 Wiley Periodicals, Inc. Sci Ed

95:670-699, 2011

\section{INTRODUCTION}

Energy is one of the most fundamental and far reaching of all scientific concepts. Biologists use energy to describe the relationships between organisms in an ecosystem; chemists interpret chemical reactions by tracking energy changes; geologists use the conservation of energy to build models that describe plate tectonics; cosmologists rely on energy conservation when deducing the shape and structure of the universe. Regardless of its application, the law governing energy is strikingly simple - the total amount of energy in any closed system must be the same at any two points in time.

It is both the simplicity of the law of conservation of energy and its wide applicability that make it a ubiquitous topic in school science, yet it is often addressed superficially in ways that are not likely to promote integrated understanding (Linn \& Eylon, 2006) in students. By integrated understanding, we mean ideas that are connected to each other in such a manner that allows learners to be aware of and be able to use relationships between various ideas. Such understanding allows learners use this relational network of ideas to explain and predict phenomena as well as solve problems (Fortus \& Krajcik, in press). In a review of the most popular textbooks used in middle school science classrooms, Kesidou and Roseman (2002) found most to be inadequate in terms of their ability to promote students' development of integrated understandings of the major ideas in science, such as energy. Among their shortcomings, the most popular school science textbooks failed to model how students can apply scientific concepts and processes in their lives outside of school. Without making connections among science concepts and between school science and students' everyday lives explicit, students are highly unlikely to do it on their own (Brown, Collins, \& Duguid, 1989).

To make such connections and to develop integrated understandings of scientific concepts like energy, curricula must provide students with opportunities to refine and reorganize their prior understandings (Bransford, Brown, \& Cocking, 2000; Duschl, Schweingruber, $\&$ Shouse, 2007). When students enter the science classroom, they have already formed their own ideas related to energy (Driver, Squires, Rushworth, \& Wood-Robinson, 1994a; Solomon, 1983; Watts, 1983), but typical physical science instruction has proven largely ineffective for helping students refine these ideas into more accurate and sophisticated conceptions (Driver et al., 1994a; Solomon, 1983).

Many widely used middle school science textbooks promote an instructional approach that focuses on straightforward calculations of energy and work idealized systems (e.g., objects falling with no air resistance, frictionless roller coasters), offers a simple operational definition for energy (e.g., "the ability to do work" or "the ability to cause a change")—even though no satisfactory definition exists (Feynman, Leighton, \& Sands, 1989), and addresses one form of energy at a time without emphasizing the importance of energy transformations in nonidealized, everyday phenomena with which students can easily interact (see Biggs, Daniel, \& Feather, 2008; DiSpezio, Linner-Leube, Lisowski, Skoog, \& Sparks, 1997; Todd, Kilpatrick, Earvolino, Garcia, \& Zapanta, 2002). In a study of textbook treatments of the 
conserved quantities of momentum and kinetic energy, Bryce and MacMillan (2009) found that applying a number-crunching approach to idealized situations may actually be the source of many student misunderstandings about why, when, and where conservation laws apply. Since many, if not most, middle school science teachers are teaching out of their primary field (Seastrom, Gruber, Henke, McGrath, \& Cohen, 2004) and these teachers tend to rely heavily on the textbook (Ball \& Cohen, 1996), middle school energy instruction often reflects the textbooks with which teachers are supplied (Roseman, Linn, \& Koppal, 2008).

The approach to middle school energy instruction taken in many textbooks aligns with assertions that young children are not yet capable of dealing with energy as an abstract physical quantity (Piaget \& Inhelder, 1971; Warren, 1986), yet recent studies indicate that such a stage-like conception of development is not entirely appropriate (Flavell, 1994). Furthermore, instructional interventions seem to play a key role in developing understandings in young children that many adults never acquire (Duschl et al., 2007; Klahr \& Nigam, 2004; Linn, Lee, Tinker, Husic, \& Chiu, 2006; Smith, Maclin, Houghton, \& Hennessey, 2000; White \& Frederiksen, 1998). When students develop understandings that are integrated rather than a collection of disconnected ideas, they are more likely to be able to apply their knowledge to new situations and continue to learn more efficiently even after instruction (Bransford et al., 2000; Duschl et al., 2007; Linn \& Eylon, 2000) - this is the idea of preparation for future learning (PFL) (Bransford \& Schwartz, 1999). To help students develop integrated understandings that promote future learning, energy instruction must be organized around learning goals based on core science ideas and involve learners in relevant contexts (Domenéch et al., 2007; Duschl et al., 2007; Roseman et al., 2008).

In response to these challenges, we developed a new unit (Fortus et al., 2005; Starr et al., 2009) to introduce middle school students to the scientific concept of energy. The unit represents a substantial departure from the typical textbook approach to energy instruction because it involves no calculations of work or energy, makes no attempt to operationally define energy, and focuses on energy transformations that occur in nonidealized phenomena that students are likely to see outside of the classroom. Because of its central focus on energy transformations in nonidealized everyday phenomena, we believe this approach gives students more of an opportunity to link their school science knowledge with their prior experiences into an integrated framework that is organized around the principle of energy transformation. By having a concept of energy that is useful in many contexts, students are well positioned to use their energy concept to interpret new information in novel situations. Because our unit was designed to help students develop a more accurate and applicable concept of energy, we hypothesized that our approach is an effective way to promote integrated understandings of energy and PFL.

In this article, we describe our instructional approach for teaching energy to middle school students and explicate the results of a between-groups comparison study in which we investigated the effects of the unit on middle school students' conceptual understanding of energy, ability to perform on assessment items targeted at the Benchmarks for Science Literacy (BSL) (American Association for the Advancement of Science [AAAS], 1993) and preparation for future energy-related learning.

\section{THEORETICAL FRAMEWORK}

Most students encounter the term "energy" in informal settings well before they enter the middle school science classroom and will therefore enter the classroom with a set of preexisting ideas, many of which do not match scientists' understanding of energy. Watts (1983) found that the vast majority of students' alternative ideas about energy could be 
classified into seven alternative frameworks: anthropocentric (energy is mainly associated with human beings), depository (some objects "have" energy, whereas others "need" it), ingredient (energy is dormant within some objects and can be released by some trigger), activity (energy is identified by overt displays - the display itself is energy), product (energy is a relatively short lived by-product of some situation), functional (energy is a very general kind of fuel for technical devices), and flow-transfer (energy is a physical fluid that is transferred in certain processes). Gilbert and Pope (1986) and Trumper (1990) later substantiated Watts' original frameworks, and Trumper added to Watts' frameworks by splitting the depository framework into two parts: passive deposit (Watts' original definition) and active deposit, or cause (energy deposits cause things to happen). Furthermore, Trumper added the transformation framework (when a process takes place, energy is transformed from one type to another) to describe the accepted scientific view. With these changes, Trumper found that $96 \%$ of 14-16-year-old students' responses to energy-related interview prompts were classifiable according to these frameworks. Trumper's addition of the transformation framework is important for assessing whether students possess an integrated understanding of energy, since using the idea of transformation to explain a phenomenon involves identifying one or more types of energy that are involved in the phenomenon and using the idea of transformation to link appropriately between them (Lee \& Liu, 2010).

In a synthesis of research into children's ideas, Driver et al. (1994b) proposed that students' energy conceptions progressed through a fairly common sequence. In this sequence, students start from a conception that is largely defined by their own sense of feeling energetic, extend that sense of energy to other living and then nonliving things, become aware of stored energy, and finally become aware of energy conservation and degradation. This sequence was not empirically derived, rather, Driver et al. constructed it from a review of other studies that used a variety of methods in a variety of populations.

Seeking to empirically construct a typical progression through the energy concept, Liu and McKeough (2005) examined United States students' responses to selected items in the TIMSS database. They classified items according to the type of conception that they represented and developed the following categories: activity/work (energy is the cause for activities), source/form (energy is stored in a variety of sources and can exist in various forms), transfer (energy can be transferred), degradation (energy is "lost" during transformations), and conservation (the total energy in a closed system must be constant). They found that all grade levels reached the activity/work competence level, and students above the fourth-grade level reached the source/form level. Middle and high school students marginally displayed an understanding of energy transfer, but neither group demonstrated an understanding of energy conservation or degradation.

Liu and McKeough suggest that their results reinforce the neo-Piagetian (see Case, 1985, 1992) assertion that maturational factors play a central role in students' ability to acquire the full energy concept, setting an upper limit on students' concept acquisition. Recognizing variation within their sample, they acknowledge that students' aptitude and instructional experiences play a role in students' concept development, but like the work of Driver et al. (1994b), Liu and McKeough's study did not include an instructional component. Without an instructional component, these studies were unable to detect the role that instruction can play (Duschl et al., 2007) in helping students develop an integrated understanding of energy.

\section{Alternative Approaches to Energy Instruction}

Our study is predicated on the idea that instruction can play a crucial role in students' cognitive and conceptual development. Yet, not all instruction is bound to be equally 
productive in this regard; in fact, students' initial ideas seem quite resistant to change in many instructional contexts (Chi, 2005). The design of instructional interventions has a great deal to do with their success or failure in helping students develop integrated understandings.

There has been much debate around how to design successful energy instruction. The common textbook approach is similar to that advocated by Warren (1982), who argued that energy should be introduced as an abstract idea developed by scientists and defined as a capacity to do work. However, common textbook approaches to energy instruction have done little to help students develop a deep conceptual understanding of energy (Bryce \& MacMillan, 2009; Duit, 1984). The lack of success of traditional science instruction in improving students conceptions has led to many theoretical contributions describing alternative instructional approaches, including presenting energy as a "stuff-like" quantity (Swackhamer, 2005), focusing on energy degradation in macroscopic systems (Pintó, Couso, \& Gutierrez, 2005), and using a systems framework to analyze energy transfers (van Huis \& van den Berg, 1993). Although many theoretical contributions exist, relatively few studies have empirically investigated the effectiveness of specific instructional approaches.

Trumper (1990) conducted one such empirical study, which investigated a conceptual change approach (Chinn \& Brewer, 1993; Nussbaum \& Novick, 1982; Stepans, 2003) to energy instruction that was intended to expose and confront students' naïve conceptions. By presenting students with "comparative events," Trumper demonstrated that students could be aided in moving away from an anthropocentric view of energy (energy is only associated with human beings) toward a more scientifically accepted view (human beings act as "energy agents"). Although such a conceptual change approach recognizes the importance of deep conceptual understanding and the fact that young students will develop their own ideas about energy prior to its formal introduction in school, it deemphasizes the explanatory power that students' initial ideas often have in their lives outside of school. Smith, diSessa, and Roschelle (1993) argue that instruction should not focus on highlighting deficiencies in students' prior knowledge, rather, it should build upon students' prior knowledge to develop new understandings that broaden the explanatory power of their initial ideas. By providing learners with opportunities to connect their naïve ideas with more sophisticated scientific ideas, curricular materials can better support learners' development of integrated understanding.

\section{The Role of Curricular Materials in Promoting Integrated Understanding}

Our unit was developed in accordance with Smith, diSessa, and Roschelle's notion that learners' naïve ideas are largely consistent with their experiences within the natural world, but that they are not well connected in an integrated framework organized around central scientific principles. As such, these naive ideas tend not to carry predictive or explanatory power sufficient to interpret a broad range of phenomena or to connect between phenomena with different surface features (Chi, Feltovich, \& Glaser, 1981).

When conceptual development occurs, students' understandings tend toward more expert understandings, but this development is unlikely to occur in an ordered, linear fashion. Rather, the process of conceptual change will likely be a nonlinear process that reflects a complex interplay of both intuitive and instructed ideas of different grain sizes. As students learn, their knowledge networks undergo a process of conceptual restructuring (Clark, 2006) and knowledge integration (Linn et al., 2004), during which students' ideas and the connections between them are redefined and reorganized. During this process of reorganization, certain ideas become more likely to be activated for certain contexts when they hold significant explanatory or less likely when they do not (Smith et al., 1993). In 
addition, new ideas may be added to the network and existing ones may be changed by coalescing with other ideas or by becoming differentiated into multiple ideas (Clark, 2006).

Instruction most effectively supports integrated understanding when it is aimed toward incorporating students' initial ideas into an integrated framework rather than discounting and replacing these initial ideas with more sophisticated ones (Smith et al., 1993). If students develop integrated understandings, they are able to connect their scientific ideas to make sense of their experiences and to explain situations they have not previously encountered (Roseman et al., 2008). Students' integrated understandings may not only be manifest as short-term learning but also as the foundation for future learning (Bransford et al., 2000; Bransford \& Schwartz, 1999; Linn \& Eylon, 2000).

To build integrated understandings, instruction must be built from coherent curriculum. To be coherent, curriculum must align with learning goals based on a set of core scientific ideas while avoiding nonessential information, make connections between new ideas and prior knowledge explicit, connect evidence to scientific ideas, and connect the ideas of science to the natural world (Roseman et al., 2008; Shwartz, Weizman, Fortus, Krajcik, \& Reiser, 2008). In order for students to activate, reorganize, and make links to their existing ideas, they must think analytically about familiar phenomena, because it is in contexts familiar to students where their initial ideas were formed and where they most conspicuously apply. By using new ideas to reason about familiar contexts, students can better understand how the newer ideas learned in school have broader explanatory power than their initial ideas and adjust their thinking accordingly.

\section{Research Questions and Hypotheses}

We investigated three research questions: How do students' conceptions of energy develop during instruction? How well are students' new conceptions of energy retained 1 year after instruction? How do energy unit participants' knowledge and concept of energy compare to those of older nonparticipants at the same school with similar academic potential/background?

We hypothesized that students' energy conceptions would become more integrated and organized around the idea of transformation during their participation in the energy unit, that these conceptions would be well maintained 1 year after instruction, and that energy unit participants would be more likely to exhibit an integrated energy conception that was organized around the central idea of transformation than were older nonparticipants from the same school (who learned about energy in a way that did not emphasize the central role of transformations in everyday phenomena). We anticipated this robust conceptual development because in course of the energy unit, participants regularly use the central principle of transformation to predict and explain real-world phenomena. By reasoning about everyday phenomena that they are likely to encounter outside of school, students are more likely to integrated understandings of science concepts (Bransford et al., 2000; Duschl et al., 2007; Linn et al., 2004).

Finally, we hypothesized that energy unit participants would be well prepared to learn about energy in their subsequent science courses. With integrated understandings, students are more likely to effectively apply their knowledge in new situations and learn more efficiently (Bransford et al., 2000; Bransford \& Schwartz, 1999; Linn \& Eylon, 2000).

\section{A NEW APPROACH TO MIDDLE SCHOOL ENERGY INSTRUCTION}

We designed the energy unit according to the principles of learning-goals-driven design using project-based pedagogy (Krajcik, McNeill, \& Reiser, 2008). According to this design 
model, we first compiled, interpreted, and elaborated the middle school energy standards in the BSL (AAAS, 1993) and National Science Education Standards (NSES) (National Research Council [NRC], 1996) and produced unit-specific learning goal statements, presented in Appendix A. Project-based curriculum involves creating a meaningful context by using a driving question to motivate, organize, and contextualize instruction; the driving question for our energy unit is "How can I use trash to power my stereo?" To fully address this question, students must learn about various types of energy (e.g., kinetic, chemical, electrical), energy transformations and conservation, energy dissipation, and energy resources. Instruction consists of 19 lessons organized into 6 lesson sets, each of which addresses a key component of energy. The duration of the unit is approximately 8 weeks.

\section{Lesson Set 1: Identifying Types of Energy (Five Lessons)}

Lesson Set 1 begins with an anchoring activity —in which a pinwheel is set in motion by burning paper beneath it-to provide an opportunity for students to use their intuitive knowledge and preconceptions to make sense out of a relevant and conceptually rich phenomenon, and it serves as a common experience that can be linked to subsequent instructional activities (Clement, Brown, \& Zeitsman, 1989; Cognition and Technology Group at Vanderbilt, 1992). At the conclusion of the anchoring activity, the teacher poses the driving question and emphasizes to the students that the goal of this unit is to find out more about energy and how it is involved in phenomena that we observe.

After the anchoring activity, Lesson Set 1 is devoted to introducing students to various types of energy. For each type of energy addressed in this unit, we have defined a set of associated indicators and factors to help students identify which types of energy are involved in phenomena and to make qualitative judgments about whether their magnitude is increasing or decreasing. An indicator is an observable physical feature of a phenomenon that indicates the involvement of a certain type of energy, whereas a factor is a characteristic that affects the amount of a particular type of energy. Indicators are a subset of factors, and both factors and indicators were extracted from the mathematical expressions that allow one to calculate the magnitude of each energy type. For example, because kinetic energy is given by the formula $(1 / 2) m v^{2}$, we identify mass and speed as factors for kinetic energy. Because the speed of an object is the observable variable that students can use to determine whether an object has kinetic energy, speed is the indicator for kinetic energy. Since mass is necessary for determining the magnitude of kinetic energy, but not sufficient for an object to have kinetic energy, it is a factor. We developed a similar set of indicators and factors for each energy type addressed in the unit. The system of indicators and factors is designed to allow students to focus on the central characteristics and behavior of each energy type without diverting their attention to the details of calculations. Appendix B shows a complete list of factors and indicators used in the energy unit.

During Lesson Set 1, students repeatedly interact with a variety of everyday phenomena to classify which energy types are involved in their operation. Such objects include toasters, glow sticks, guitars, portable music players, candles, and many others that the students are likely to see in their lives outside of school. By choosing everyday objects such as these, students are more likely to connect their school learning with their naïve ideas and intuitive knowledge (diSessa, 2000; Smith et al., 1993).

\section{Lesson Set 2: Energy Transformations (Two Lessons)}

In Lesson Set 2, students continue to work with everyday phenomena, but begin to focus on those that involve some event which clearly delineates a "before" and "after" condition, 
such as a jack-in-the-box, rubber band slingshots, inverted half racquetballs, instant heat packs, and others. For example, students classify the energy types present in a yo-yo before it is dropped, during its fall, and after it has reached the bottom of the string and is spinning. Then, they examine the energy types they listed in the "during" phase (as the yo-yo is descending) and, using their knowledge of the factors for each energy type, determine whether each type of energy was increasing or decreasing. By noticing that an increase in one type of energy is always concomitant with a decrease in at least one other type, students begin to accept that these types of energy are actually transforming into each other.

\section{Lesson Set 3: Energy Conservation (Four Lessons)}

In line with BSL recommendations for middle school students, we chose to introduce energy conservation as a qualitative characteristic of energy rather than a mathematical principle. If students accept the idea that an increase in one type of energy is always accompanied with a decrease in another type of energy, and vice versa, they are positioned to understand that a decrease in all types of energy in an apparatus (an apparent energy loss) must be accompanied by an increase in some energy type(s) elsewhere. By investigating apparatuses in which energy is clearly not conserved (a bouncing ball or a marble rolling back and forth on a U-shaped track), students are likely to recognize that they notice decreases in the amount of energy in the system but be unable to identify the associated increases in other energy types (e.g., thermal energy in the surroundings) that must be occurring. To help students accept the idea that energy in a system can be transferred to thermal energy in the surroundings, teachers collide a pair of steel spheres with a piece of paper in between them. Thermal energy produced during the collision is sufficient to burn a hole in the paper where the spheres collided. This demonstration serves as powerful evidence that thermal energy can be produced even when things do not feel hot and positions students to accept that thermal energy is often transferred to the surroundings when all of the energy types in an apparatus decrease. Thus, the concepts of energy conservation and dissipation are developed in conjunction with each other and are built upon the idea of energy transformation.

\section{Lesson Set 4: Answering the Driving Question (One Lesson)}

At this point, students are prepared to understand how burning trash is connected to producing music through stereo speakers. In Lesson Set 4, students learn about the structure and function of a steam turbine and, more generally, electric generators. Armed with this knowledge and their previous study of energy types and transformations, they are capable of describing a chain of events that must occur to use trash to power a stereo. In this lesson set, students describe the energy transformations that must take place when trash is burned to heat steam, and this steam is used to turn a turbine to produce the electricity that is ultimately used to produce music through the vibration of a speaker membrane.

\section{Lesson Set 5: Design Challenge (Two Lessons)}

After students are capable of "answering" the driving question, they engage in a design project that involves a series of energy transformations on the way to accomplishing a task of the students' choosing, such as frying an egg or peeling a banana. This project provides students with an important opportunity to refine their understanding of energy because it encourages them to reflect on what they know (Davis, 2003) and to iteratively develop and refine plans for a machine that exhibits many energy transformations (Fortus, Dershimer, 


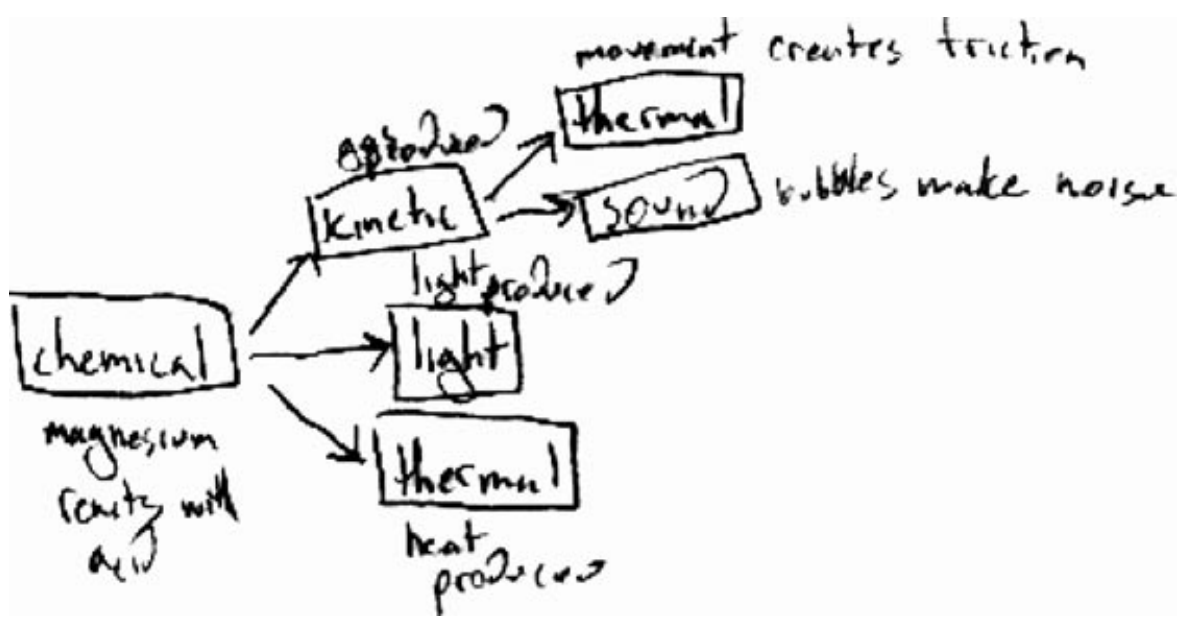

Figure 1. Student-created transformation diagram describing the energy transformations that occur when a strip of magnesium reacts with acid.

Krajcik, Marx, \& Mamlok-Naaman, 2004). When completed, students' contraptions are assessed based upon the number and variety of energy transformation that their machine accomplished and upon the quality of their energy transformation diagrams. These diagrams are a graphical method by which students keep track of the energy transformations that occur in some device or system. Visual representations such as these are an important tool for students as they develop and refine their understanding of scientific concepts and processes (Wu, Krajcik, \& Soloway, 2001). Energy transformation diagrams are similar to the energy flow diagrams used by scientists who study energy systems, but energy transformation diagrams display only changes in energy types and do not include quantitative information regarding efficiency or ratios of energy types. An example of an energy transformation diagram is shown in Figure 1.

\section{Lesson Set 6: Energy Resources (Five Lessons)}

In the last lesson set, students turn their attention to Earth's energy resources. Using what they have learned about energy during the preceding lesson sets, students research the availability of particular resources and the consequences of their use to develop an energy plan for a city of their choosing.

In the final lesson of the unit, students read a fictitious newspaper article that proclaims, "Energy can be easily defined as the ability to run machines. We are in an 'energy crisis' because we have used so much energy that there is not enough in the world to last for much longer." Students respond to this article by providing a better explanation of what is meant by the term "energy" and what it means to be in an energy crisis. An ideal response to this prompt demonstrates students' understanding that knowing what energy does is more important than trying to define what it $i s$, that energy is transformed in phenomena, that energy cannot be created or destroyed, and that energy transformations usually produce thermal energy that is difficult to reuse.

Throughout the unit's approximately 8 -week instructional sequence, students continually use the idea of energy transformation to qualitatively describe familiar systems, and they are not asked to calculate magnitudes of energy types or to commit a simple definition for energy to memory. The focus of this approach and the time dedicated to helping 
students build an understanding of energy that is organized around the central idea of transformation represents a substantial departure from traditional middle school energy curricula.

\section{METHODS}

\section{Research Setting}

This study was conducted in a small independent school, located in a Midwestern college town, that contains both a middle and a high school. The school, Fairmeadows (pseudonym), enacted the energy unit as a part of their eighth-grade science course during both the 20042005 (Enactment 1) and 2005-2006 (Enactment 2) school years. Prior to the 2004-2005 school year, eighth-grade science students at Fairmeadows did not participate in the energy unit but studied energy in a different way. These students learned about energy during five project-based units that were organized around a yearlong theme of energy; each unit dealt with a different aspect of energy (e.g., energy in living systems, electricity, weather, and sound) without emphasizing the central role of transformations in familiar everyday phenomena.

Fairmeadows is characterized by relatively low student mobility and faculty turnover and a high degree of collaboration between teachers within each grade level. These characteristics enabled us to design a cross-sectional study with a longitudinal component to examine whether a focus on energy transformations in everyday phenomena promotes students' development of a more integrated understanding of energy compared to older students who had the same teachers and a very similar eighth-grade science curriculum, but who studied energy in a way that more closely resembled a traditional approach to middle school energy instruction.

\section{Overview of Energy-Related Learning Opportunities at Fairmeadows}

When interviewed, Fairmeadows teachers reported that there are many energy-related learning opportunities in the science courses at Fairmeadows, but the majority of explicit energy-focused instruction occurs in eighth-grade science and in the 11th-grade physics course. A science student following the traditional science progression at Fairmeadows will experience the following energy related instruction: An 8th-grade science course organized around the theme of energy, a 9th-grade biology course in which they learn about energy transfer and transformation through ecological and biomolecular phenomena (such as photosynthesis and respiration), a 10th-grade chemistry course in which they learn about energy transfer in chemical phenomena, and an 11th-grade physics course in which they focus on the quantitative conservation of mechanical energy in closed, often idealized systems. When the energy unit was incorporated into the eighth-grade science course, an existing unit called "Where Do Plants Get Their Energy?" was rolled into the unit called "Where Do You Get All of Your Energy?" and replaced with the new energy unit. The new energy unit, "How Can I Use Trash to Power My Stereo?," was one of four project-based units taught during the year and instruction took place during the third 9-week period of the year. Apart from the inclusion of the energy unit in the eighth-grade science course, the content of Fairmeadows science courses has remained almost entirely unchanged during the years relevant to this study. Therefore, 10th-grade chemistry and 11th-grade physics students have had more energy-related learning opportunities than students in eighth grade (Cohort 2) and ninth grade (Cohort 1), but those opportunities did not include a unit focusing on energy transformations in nonidealized phenomena during their eighth-grade year. Prior 
to the introduction of the energy unit, eighth-grade energy instruction was characterized by a more piecemeal approach to energy by focusing on one type of energy at a time without emphasizing transformation, and it focused largely on idealized phenomena that students were unlikely to observe directly outside of school.

\section{Data Sources}

To address our research questions, we administered measures to elicit students' conceptions of energy and assess their content knowledge related to energy.

During their involvement in the energy unit, all participants completed a unit pre/posttest aligned to the learning goals of the unit (based on NSES and BSL), which was written by the unit developers. The unit test was identical for both enactments.

To compare content knowledge across grade levels, we administered an energy content questionnaire that consisted of items that were in development by members of Project 2061 to address middle school energy benchmarks. Although these items were still in the pilot stage of development, they provided distal (Ruiz-Primo, Shavelson, Hamilton, \& Klein, 2002) criterion-referenced items assessing the benchmarks that the energy unit was designed to address. The AAAS Project 2061 item development process is described in DeBoer, Dubois, Herrmann Abell, \& Lennon (2008) and in DeBoer et al. (2008). We administered the energy concept questionnaire to all 8-11th-grade students at Fairmeadows who were following the 8th Grade Science-Biology-Chemistry-Physics course sequence (chemistry and physics are not required courses at Fairmeadows, so these groups were smaller and more self-selected for an interest in science). All questionnaires were administered in the final weeks of the school year.

To track and compare students' energy conceptions, we administered an energy concept questionnaire that consisted of questions used in past studies to categorize students' energy conceptions according to Watts' and Trumper's frameworks (Bliss \& Ogborn, 1985; Kruger, Palacio, \& Summers, 1992; Trumper, 1993, 1998), as well as items adapted from a version of the Energy Concept Inventory (Swackhamer \& Hestenes, 2003). Each item consists of a statement regarding the role of energy in a scenario (e.g., "In this circuit, the battery has the energy and the light bulb uses the energy until it is gone"), and respondents check whether they agree, disagree, are unsure, or do not understand the statement. Scenarios in the energy concept questionnaire were chosen to be separate from phenomena specifically addressed in the energy unit. We administered the energy concept questionnaire to all 8-11th-grade students at Fairmeadows who were following the 8th Grade Science-Biology-ChemistryPhysics course sequence. All questionnaires were administered in the final weeks of the school year.

To more thoroughly investigate students' developing conceptions and assess the extent to which their understanding was integrated around the idea of transformation, we asked teachers to select a group of 16 students per grade level to be interviewed ( $>25 \%$ of the sample), whom they felt were representative of their students (in the Results section, we report our analysis regarding the representativeness of selected students). One researcher interviewed all the students using the interview-about-instances approach (Osborne \& Gilbert, 1980). In this approach, an interviewer shows students a number of pictures that illustrate various everyday situations and asks whether each picture illustrates the student's idea of energy. The pictures illustrate scenarios that students are likely to interpret as instances, noninstances, and borderline cases of energy (e.g., a person eating a meal, a light bulb and battery in a circuit, a melting ice cube, a firecracker). Once a student identifies whether the picture is an illustration of her idea of the concept, the researcher asks the student to describe her reasoning. The researcher, using the students' language 


\section{TABLE 1}

Overview of Measures Administered to Students

\begin{tabular}{cccccc}
\hline & & \multicolumn{5}{c}{ Measure } \\
\cline { 3 - 6 } & Year & $\begin{array}{c}\text { Unit } \\
\text { Test }\end{array}$ & $\begin{array}{c}\text { Energy Content } \\
\text { Questionnaire }\end{array}$ & $\begin{array}{c}\text { Energy Concept } \\
\text { Questionnaire }\end{array}$ & $\begin{array}{c}\text { Student } \\
\text { Interviews }\end{array}$ \\
\hline $\begin{array}{c}\text { Cohort 2 } \\
\text { (8th grade) }\end{array}$ & $2005-2006$ & $\sqrt{ } \sqrt{ }$ & $\sqrt{ } \sqrt{ }$ & $\sqrt{ } \sqrt{ }$ & $\sqrt{ } \sqrt{ } \sqrt{ }$ \\
$\begin{array}{c}\text { Cohort 1 } \\
\text { (9th grade) }\end{array}$ & $2004-2005$ & $\sqrt{ } \sqrt{ }$ & & & $\sqrt{ } \sqrt{ } \sqrt{ }$ \\
$\begin{array}{c}\text { Chemistry } \\
\text { students } \\
(10 t h \text { grade) }\end{array}$ & $2005-2006$ & & $\sqrt{ }$ & $\sqrt{ }$ & $\sqrt{ }$ \\
$\begin{array}{c}\text { Physics } \\
\text { students } \\
(11 \text { th grade) }\end{array}$ & $2005-2006$ & & $\sqrt{ }$ & $\sqrt{ }$ & \\
\hline
\end{tabular}

Note. Each check $(\sqrt{ })$ indicates one administration of the measure.

when possible, then probes student responses. This approach has been used in past studies to investigate students' conceptions of energy (Kruger, 1990; Trumper, 1990, 1993, 1998; Watts, 1983; Watts \& Gilbert, 1983), and the illustrated scenarios we used were adapted from these studies. As with the energy concept questionnaire, scenarios were chosen to be separate from phenomena specifically addressed in the energy unit.

We interviewed energy unit participants before the unit, after Lesson Set 1, after Lesson Set 3, and after the unit (for both enactments). In addition, 9th, 10th, and 11th graders were interviewed once at the end of the school year in which Enactment 2 took place.

All together, data in this study were collected from four student groups over the course of 2 years. Table 1 provides an overview of the measures administered during the study.

\section{Scoring of Measures}

To score the learning goals test, we assigned students one point for every correct answer to multiple-choice questions ( 21 points possible) and one point for every relevant and correct statement (e.g., identifying a type of energy involved in a phenomenon, stating that energy cannot be created/destroyed) in their responses to open-ended questions (26 points possible). One scorer rated all students' responses, and a second scorer randomly selected $10 \%$ of the tests and scored them independently. This process yielded an interrater reliability of more than $97 \%$.

To score the energy content questionnaire, we assigned students one point for every correct answer to each multiple-choice question. Since this measure did not contain openended items, we did not involve multiple scorers to test for interrater reliability.

To score to the energy concept questionnaire, we asked a group of Ph.D.-level physicists, science educators, and working scientists from a variety of fields to complete the questionnaire. After receiving 17 returned questionnaires, we searched for items that achieved consensus, which we defined to be more than $80 \%$ (14 of 17) of the experts answering a question the same way. If a student answered in this way as well, they were awarded a point. The energy concept questionnaire measures the extent to which student ideas about energy are aligned with those of experts, but it does not directly measure the level of students' 
knowledge integration since students do not have the opportunity to demonstrate linkages between their ideas. To assess integrated understanding, we analyzed students' interview responses.

To code the interviews, one scorer listened to audiotapes of the interviews and coded them according to the frameworks that the student seemed to exhibit. A second scorer then randomly selected 12 interviews ( $>10 \%$ of the data set) and coded them independently. This process resulted in an interrater reliability of better than $97 \%$. Among the framework codes, eight represented alternative conceptions and were not considered evidence of an integrated understanding. Only the transformation framework code represented evidence of an integrated understanding because to earn this code, students must identify two or more types of energy that were relevant to a situation and use the idea of transformation to link them. This method for identifying an integrated understanding of energy is in line with that used by Lee and Liu (2010), who measured a "knowledge integration" construct by assessing whether students evoked ideas (e.g., food has chemical energy) and linked them appropriately (e.g., chemical energy in food is converted to mechanical energy when a person pushes a bicycle) in their analysis of energy-related situations. The following is an example of an interview response, which is indicative of an understanding that is integrated around the idea of transformation (given by a student from Cohort 1 in response to a scenario depicting an electric heater):

It has electrical energy, chemical energy, heat energy, light energy, uh, because it starts with chemical energy in the power source and that changes into electrical energy which then goes to the heater and is transformed into heat energy and light energy.

In this response, the student identifies several types of energy that are involved in the function of an electric heater and uses the idea of transformation to describe how the types of energy are related to each other when a heater is operating. This ability to connect between ideas to make sense of everyday scenarios is a hallmark of an integrated understanding (Duschl et al., 2007; Fortus \& Krajcik, in press; Linn \& Eylon, 2000; Roseman et al., 2008).

Along with coding the interviews according to the frameworks they exhibited, we conducted a qualitative inductive analysis to look for themes within and across students in an effort to more richly describe students' conceptual development during their participation in the unit.

\section{RESULTS}

In this section, we report results from each of our measures to describe energy unit participants' conceptual development during the unit, characterize their conceptions 1 year after instruction, and compare participants' understanding of energy to that of older nonparticipants in the same school. Overall, our results suggest that the energy unit helps students develop a concept of energy that is well integrated around the central principle of transformation, meet energy-related national standards and benchmarks and become better prepared for future learning about energy.

\section{Comparison of Interviewed and Noninterviewed Students}

To check whether interviewed students were indeed representative of their noninterviewed classmates, we computed a one-way ANOVA between interviewed and noninterviewed students for the learning goals test, energy concept questionnaire, and energy content questionnaire. Table 2 shows these results. 
TABLE 2

ANOVA Results Comparing Interviewed Students and Their Classmates ${ }^{a}$

\begin{tabular}{|c|c|c|c|c|}
\hline & \multicolumn{2}{|c|}{ Mean $(S D)$} & \multirow[b]{2}{*}{$d f$} & \multirow[b]{2}{*}{$t$-Statistic } \\
\hline & Interviewed Students & Noninterviewed Students & & \\
\hline \multicolumn{5}{|c|}{ 8th-grade students (Cohort 2) } \\
\hline \multicolumn{5}{|l|}{ Learning goals test } \\
\hline Pretest & $15.0(3.1)$ & $15.2(4.3)$ & 77 & -0.033 \\
\hline Posttest & $26.5(4.3)$ & $27.1(5.1)$ & 77 & -0.265 \\
\hline Gain & $11.6(4.7)$ & $11.6(4.9)$ & 74 & 0.000 \\
\hline \multicolumn{5}{|l|}{ Concept questionnaire } \\
\hline Pretest & $8.5(2.6)$ & $8.1(2.8)$ & 75 & 0.299 \\
\hline Posttest & $11.3(2.3)$ & $11.3(1.8)$ & 77 & 0.001 \\
\hline Gain & $2.8(2.4)$ & $3.2(2.7)$ & 72 & -0.023 \\
\hline \multicolumn{5}{|l|}{ Content questionnaire } \\
\hline Pretest & $6.5(2.0)$ & $6.7(2.1)$ & 74 & -0.097 \\
\hline Posttest & $9.0(3.0)$ & $9.5(2.4)$ & 74 & -0.375 \\
\hline Gain & $2.5(2.0)$ & $2.8(2.7)$ & 68 & -0.150 \\
\hline \multicolumn{5}{|c|}{ 9th-grade students (Cohort 1) } \\
\hline \multicolumn{5}{|l|}{ Learning goals test ${ }^{b}$} \\
\hline Pretest & $15.6(5.2)$ & $13.1(4.8)$ & 50 & $2.86 \sim$ \\
\hline Posttest & $27.7(4.0)$ & $27.9(5.2)$ & 51 & -0.012 \\
\hline Gain & $12.1(5.7)$ & $14.9(5.7)$ & 49 & -2.47 \\
\hline Concept questionnaire & $11.5(1.4)$ & $10.5(2.4)$ & 53 & $2.95 \sim$ \\
\hline Content questionnaire & $10.3(2.0)$ & $10.3(2.1)$ & 53 & 0.009 \\
\hline \multicolumn{5}{|c|}{ 10th-grade students (chemistry) } \\
\hline Concept questionnaire & $7.5(2.5)$ & $8.7(2.4)$ & 33 & -2.62 \\
\hline Content questionnaire & $8.4(1.7)$ & $8.8(1.9)$ & 33 & -0.424 \\
\hline \multicolumn{5}{|c|}{ 11th-grade students (physics) } \\
\hline Concept questionnaire & $10.4(3.2)$ & $10.5(2.8)$ & 19 & -0.037 \\
\hline Content questionnaire & $11.3(2.4)$ & $11.2(2.3)$ & 27 & 0.010 \\
\hline
\end{tabular}

${ }^{* * *} p \leq .001 ;{ }^{* *} p \leq .01 ;{ }^{*} p \leq .05 ; \sim p \leq .1$.

a Only students who had attended Fairmeadows since the beginning of their 8th-grade year were included in this analysis.

${ }^{b}$ Test was taken during the previous school year.

This analysis showed that we have no reason to reject the assumption that interviewed students were representative of their peers.

\section{Conceptual Development During Instruction}

Student interview data allowed us to examine how conceptual development occurred during the unit. Students in both Enactments 1 and 2 followed a similar course of conceptual development. Figures 2 and 3 show the prevalence of frameworks per interview round for Enactments 1 and 2.

While the prevalence of interview frameworks per interview round was not identical between enactments, it was quite similar. Combining the results shown in Figures 2 and 3 with individual students' interview transcripts, we identified three themes in students' responses. First, students moved toward a more integrated understanding of energy as characterized by the transformation framework. Whereas few students began the unit using 


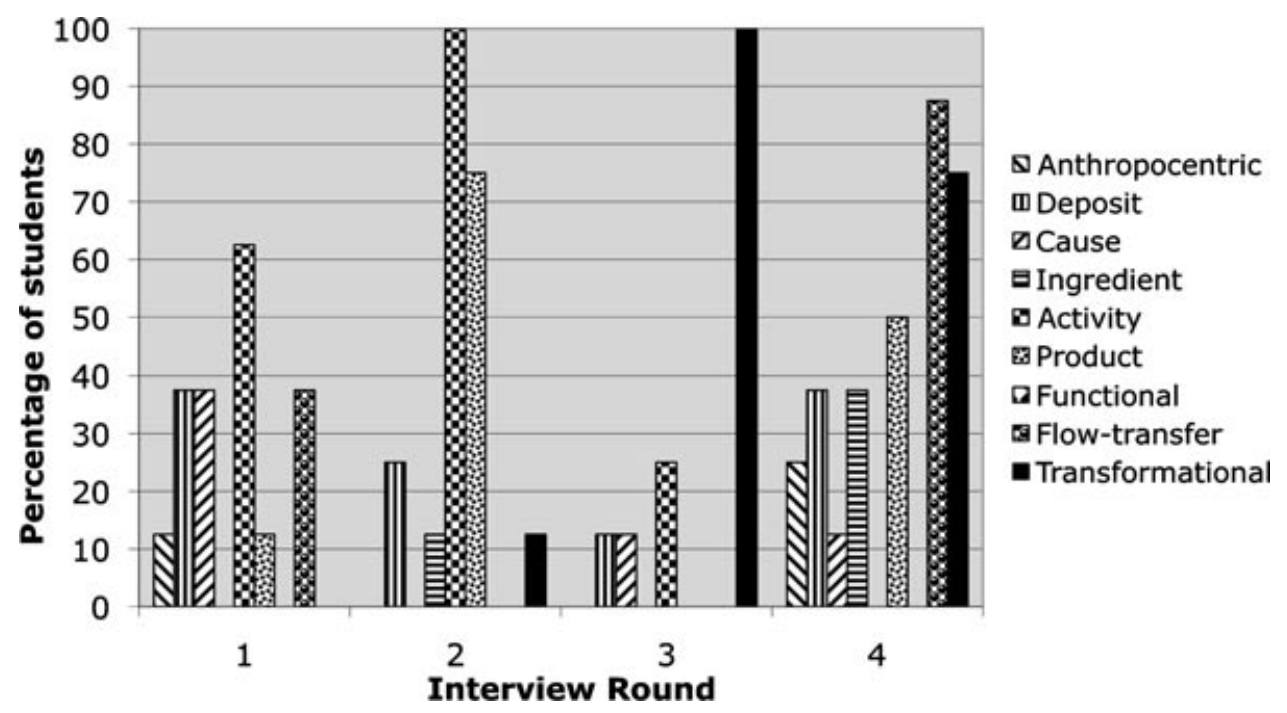

Figure 2. Percentage of students in the interview sample who exhibited particular frameworks, by round, during Enactment $1(N=8)$.

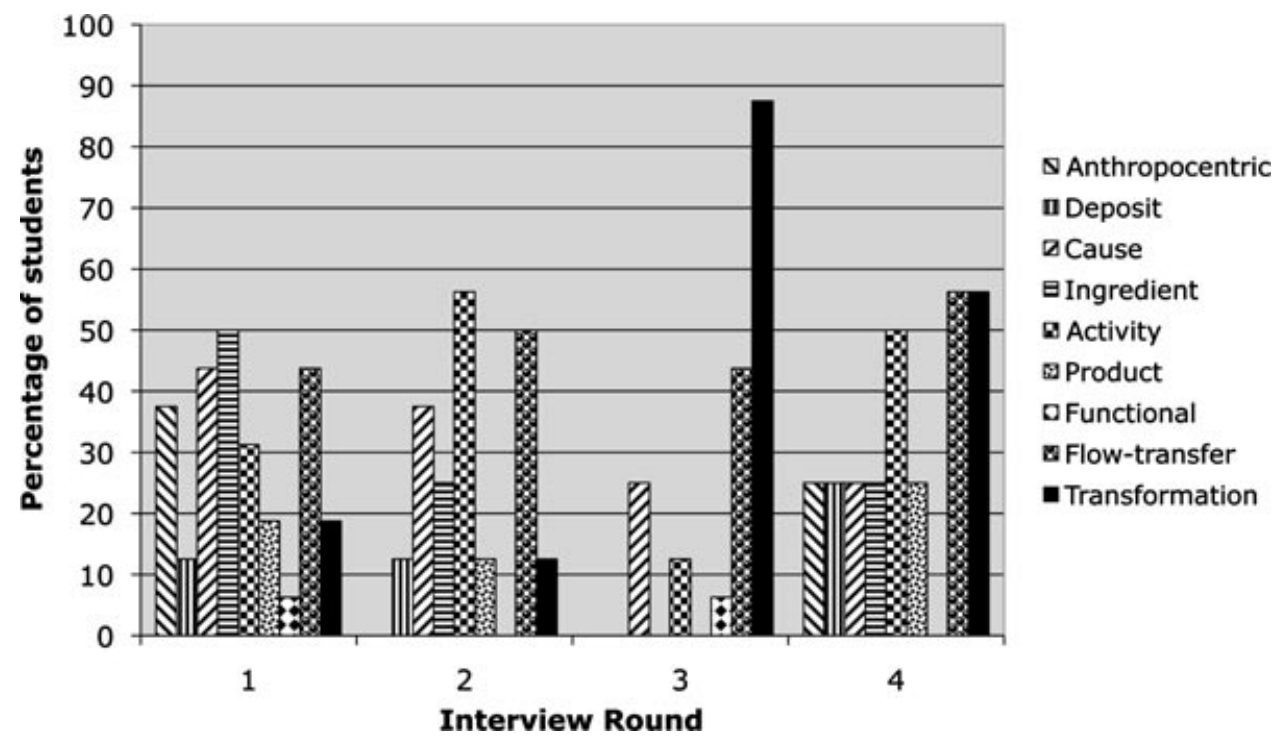

Figure 3. Percentage of students in the interview sample who exhibited particular frameworks, by round, during Enactment $2(N=16)$.

the idea of energy transformation to link between ideas when analyzing energy scenarios, most did so at the conclusion of the unit. Furthermore, students exhibited fewer alternative frameworks at the conclusion of the unit than they did prior to instruction.

Second, students' progression toward the transformation framework was not smooth. The second round of interviews occurred immediately after Lesson Set 1, during which students learn to identify types of energy based upon the presence of their indicator. In this round of interviews, students' commonly displayed the activity and/or product frameworks, in which students confuse energy with the action itself and/or view energy as a temporary product 
of some action. It is likely that students were, at this point, conflating energy types with their indicator. This conflation is likely not problematic at this point because students have not yet learned about energy transformation. After learning about energy transformation in Lesson Sets 2 and 3, nearly all students used the idea of energy transformation to link energy types to each other when analyzing interview scenarios. Although the prevalence of the transformation framework faded somewhat in the fourth interview round in favor of previously held ideas, it was still displayed by a majority of interviewees.

Third, we noticed that a deep understanding of energy conservation remained elusive for many eighth-grade students. While neither the BSL nor NSES recommend introducing middle school students to the quantitative law of energy conservation, the energy unit introduces students to the qualitative idea that energy is neither created nor destroyed. During their interviews, some students' seem to have combined this idea of qualitative conservation with the activity framework to account for what happens to energy types when they are no longer present. For example, the following exchange occurred in response to a second round interview scenario depicting a lit firecracker:

Interviewer: After the firecracker has exploded, what happens to the types of energy that you mentioned?

Student: They, well, they don't disappear, but they're not used anymore, like, the heat created by the fuse dies down, and you can touch the firecracker again and throw it away.

Interviewer: When you said that they don't disappear, why did you say that?

Student: Kinetic energy doesn't just, poof, it's there. It's always going to be there, like, even though that's sitting there, if I kick it, it would move, and that's kinetic energy, but before, it's not in use, but it's there.

This student seems to believe that the maxim "energy cannot be created nor destroyed" applies to each type of energy individually, and it is noteworthy that this type of misunderstanding was not exhibited during the first round of interviews in either enactment. It is possible that learning a fairly in-depth indicator and factor framework prior to learning about energy transformation leaves students to make their own conclusions about where energy comes from or where it goes when they do not observe the indicator for a particular energy type. Immediately after instruction, this type of response was less prevalent (exhibited by fewer than half of participants), although it still existed among a cadre of students.

\section{Student Conceptions 1 Year After Instruction}

Despite the presence of some misunderstandings, students generally moved toward the transformation framework during instruction. Although it is reasonable to expect some deterioration of students' conceptual understanding over the year since they had undergone explicit instruction on the nature and behavior of energy, we observed that Cohort 1 interviewees' conceptions seemed to have improved over the year since their participation in the energy unit. Among Cohort 1 students interviewed in both eighth and ninth grade, we observed a decrease in the number of students exhibiting undesirable frameworks and an increase in the number of students exhibiting the transformation framework. Figure 4 shows these results.

Besides displaying fewer alternative conceptions as a group, individual students seemed to have progressed toward a more sophisticated understanding of energy transformation. Allen (pseudonym) is a good example of this. When shown the scenario depicting a battery, light bulb, and a switch, Allen's response in eighth grade was as follows: 


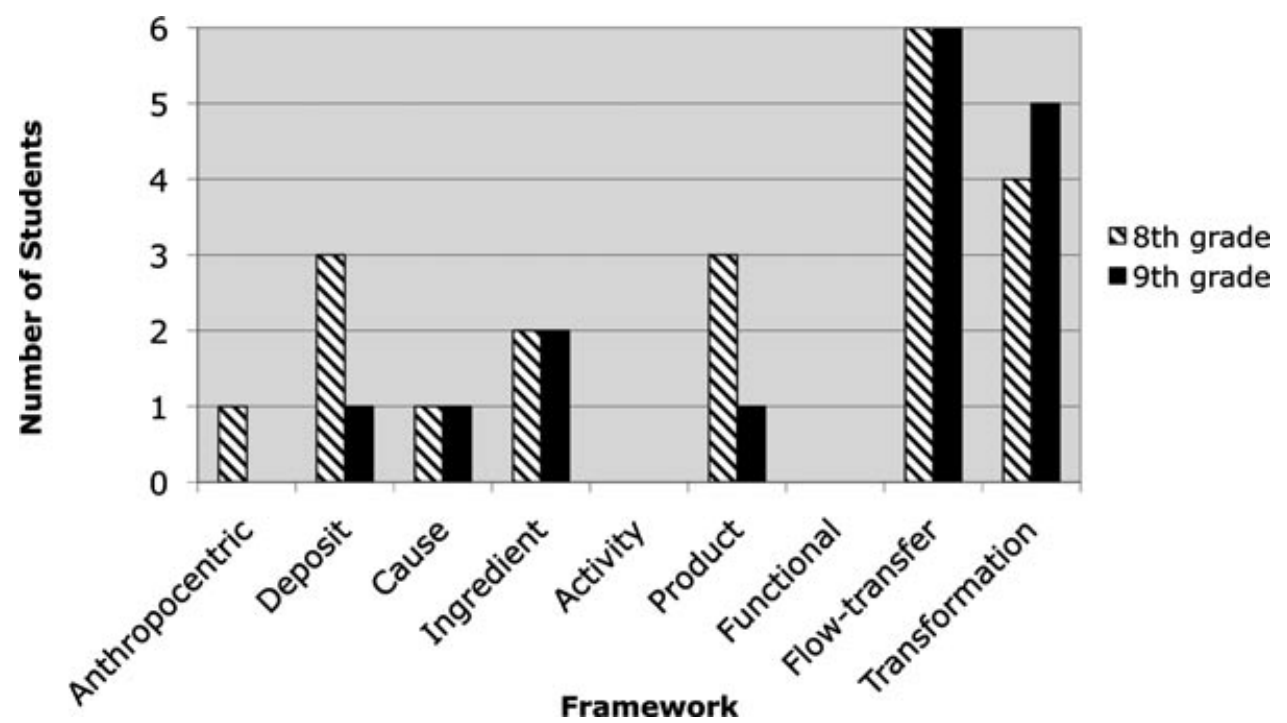

Figure 4. Comparison of energy frameworks exhibited by cohort one students who were interviewed during their eighth-and ninth-grade year $(N=6)$.

Allen: The battery converts chemical energy to electric energy through some process, which, I have no idea what it does. And since it will burn the chemicals inside of the battery, it will slowly deplete until it has none left.

Interviewer: After the battery runs out, what happens to the light energy and thermal energy and the other types that you mentioned?

Allen: They all drop. They're all, well, the light bulb goes out so they all just stop because there's no more electricity. I'm pretty sure that's what happens.

While he invoked the idea of transformation, he seemed to be teetering on the edge of an activity framework as well, because he indicated that as the battery runs out, the energy types just "stop." He did not use the ideas of transformation and conservation to explain what had become of those energy types. A year after his participation in the energy unit, Allen responded to the same scenario during his ninth-grade year:

Allen: The electrical and I suppose some of the chemical energy in the filament is transferred over to the same amount of energy in light and heat.

Interviewer: You mentioned "the same amount of energy." Why is that the same amount?

Allen: Energy is never created or destroyed, it is only reassembled, I guess, in the equation. It's an equation, it's equal, like, that's the definition. It also works to a certain extent with mass.

Although his understanding of the function of a light bulb is somewhat flawed, Allen stressed that there is as much energy after the transformation process as before it, and he alluded to the fact that conservation of energy is defined by a mathematical equation. 
The improvement of Cohort 1 students' energy conception occurred during their biology course, which included many energy-related learning opportunities such as photosynthesis and respiration, but no instructional unit dedicated to the nature and behavior of energy.

\section{Energy Conceptions Across Grade Levels}

Prior to the introduction of our energy unit at Fairmeadows, eighth-grade science instruction was organized around the theme of energy but did not emphasize the central importance of transformations in everyday phenomena. The most recent students to take 8th-grade science without participating in the energy unit were in 10th and 11th grade at the time of the study. Student interviews revealed substantial differences between energy unit participants and these older nonparticipants. Figure 5 shows the results of these interviews.

While $56 \%$ of Cohort 2 students and $80 \%$ of interviewed Cohort 1 students who were interviewed exhibited the transformation framework, only $19 \%$ of chemistry students and $44 \%$ of physics students exhibited the transformation framework during their interviews. Results of a chi-square test suggest that these differences are not likely due to chance alone, $\chi^{2}(3, N=63)=12.14, p \leq .01$. It is likely that the differences are due to the heavy emphasis that the energy unit places on interpreting everyday phenomena within an energy transformation perspective. However, even though more students in Cohorts 1 and 2 grade exhibited the transformation framework than students in 11th-grade physics, the typical physics student who exhibited a transformation framework demonstrated a far more sophisticated understanding of energy transformation and conservation-as characterized by invoking more correct ideas about energy and providing more links based on energy transformation and conservation-than did the typical eighth-grade science student who exhibited the transformation framework. This is not surprising since physics students are a more select group who have had more opportunities to develop and refine sophisticated understandings.

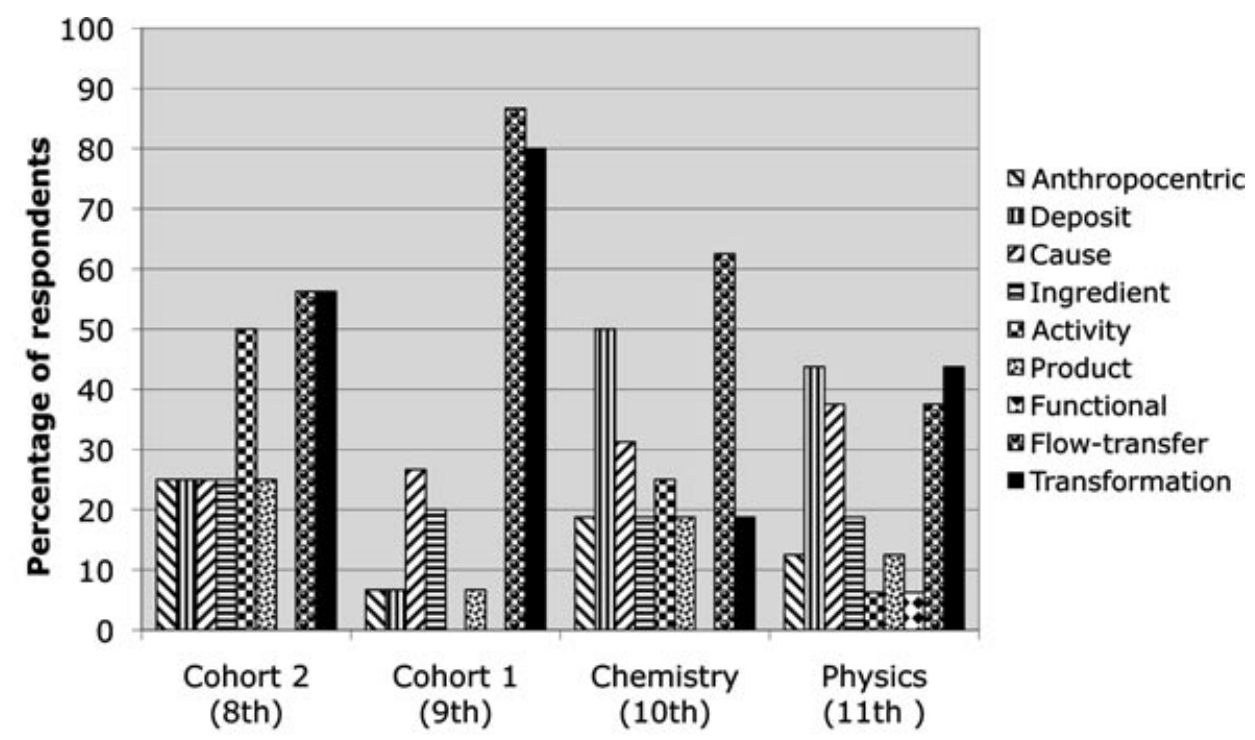

Figure 5. Energy frameworks present among interviewed Cohort 2, Cohort 1, chemistry, and physics students at Fairmeadows who have been enrolled there since the beginning of their eighth-grade year $(N=63)$. 


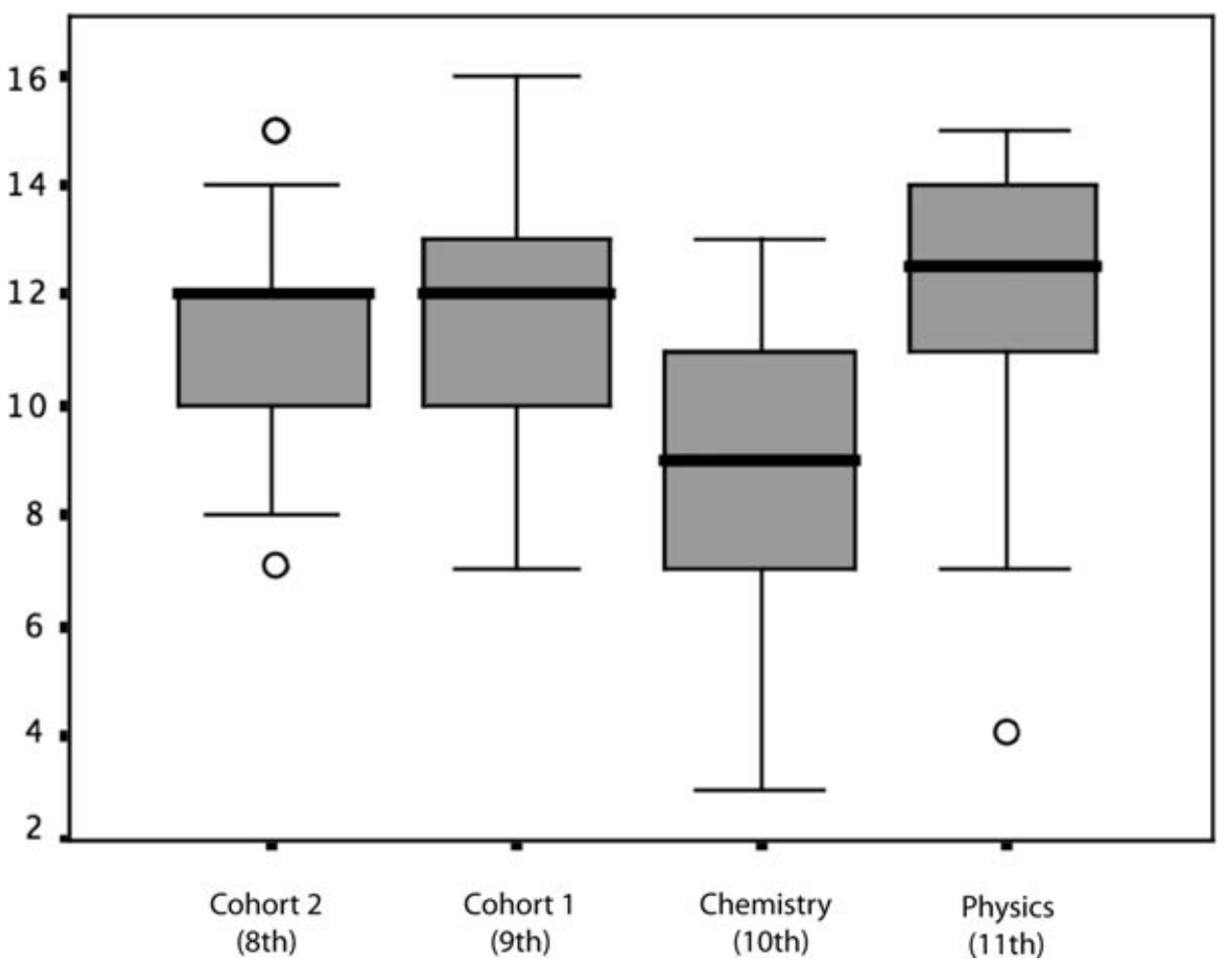

Figure 6. Boxplots showing the distribution of scores on the energy concept questionnaire.

\section{Results From Energy Concept Questionnaire}

The energy concept questionnaire allowed us to assess noninterviewed students' energy conceptions and to quantitatively measure the degree of conceptual alignment between students and experts. Figure 6 shows box plots of the distribution of scores on the energy concept questionnaire by grade level.

We compared between each grade level using a one-way ANOVA with orthogonal contrasts. These results are shown in Table 3.

To the degree that students' responses to the energy concept questionnaire match up to those of experts, Cohort 2 , Cohort 1 , and physics students were virtually the same-despite the fact that the physics students are the oldest group in this study, have had the most science instruction, and are the most self-selected for an interest in science. Compared to

\section{TABLE 3}

\section{Contrasts Between Grade Levels on the Energy Concept Questionnaire}

\begin{tabular}{lcc}
\hline & $d f$ & $t$-Statistic \\
\hline Cohort 2 vs. Cohort 1 & 187 & -0.657 \\
Cohort 2 vs. chemistry & 187 & $4.94^{* * *}$ \\
Cohort 2 vs. physics & 187 & -0.972 \\
Cohort 1 vs. chemistry & 187 & $5.17^{* * *}$ \\
Cohort 1 vs. physics & 187 & -0.471 \\
\hline
\end{tabular}

$$
{ }^{* * *} p \leq .001 ;{ }^{* *} p \leq .01 ;{ }^{*} p \leq .05 ; \sim p \leq .1 \text {. }
$$


TABLE 4

Pearson Correlations Between Interviewed Students' Energy Frameworks and Their Energy Concept Questionnaire Score $(N=57)$

\begin{tabular}{lc}
\hline Energy Framework & $\begin{array}{c}\text { Pearson Correlation With } \\
\text { Energy Concept Questionnaire Score }\end{array}$ \\
\hline Anthropocentric & $-.249 \sim$ \\
Deposit & -.169 \\
Cause & -.083 \\
Ingredient & -.102 \\
Activity & -.079 \\
Product & $-.300^{*}$ \\
Functional & $-.331^{*}$ \\
Flow-transfer & .072 \\
Transformation & $.558^{* * *}$ \\
\hline
\end{tabular}

${ }^{* * *} p \leq .001 ;{ }^{* *} p \leq .01 ;{ }^{*} p \leq .05 ; \sim p \leq .1$.

chemistry students, who were also an older and more select group, Cohort 2 and Cohort 1 students' mean scores were $26 \%$ and $28 \%$ higher, respectively.

Cross-grade level results from the energy concept questionnaire mirror results from the student interviews. To explore the alignment between these measures, we computed Pearson correlation coefficients between the frameworks students exhibited in their interview responses and their energy concept questionnaire score, and we found that only the transformation framework has a strong positive relationship with students' scores on the energy concept questionnaire. These results are shown in Table 4.

Although the energy concept questionnaire does not directly measure integrated understanding, the relationship between the transformation framework and students' concept questionnaire scores makes sense since the questionnaire measures the degree of conceptual alignment between students and experts, and expert understandings are well-integrated around central principles like energy transformation (Chi et al., 1981).

Taken together, results from the energy concept questionnaire and student interviews suggest that participation in the energy unit helped students develop ideas about energy that were more aligned with experts and more integrated around the central principle of transformation, and that it helped them to do so earlier than they otherwise might have.

\section{Results From Energy Content Questionnaire}

While helping students develop a more sophisticated energy conception was a central goal of the unit developers, the curriculum was primarily designed to address the middle school national standards and benchmarks dealing with energy. To assess whether the energy unit helps students meet these benchmarks, we compared students' scores on the energy content questionnaire by computing a one-way ANOVA with orthogonal contrasts. The grade level means and ANOVA results are shown in Tables 5 and 6, respectively.

These results suggest that from both Cohort 1 and Cohort 2 students are in a better position to succeed on assessments targeted the middle school energy benchmarks than are the older chemistry students who did not participate in the energy unit. Physics students, who outperformed all groups, seem to be in the best position to succeed on benchmark assessments. This is no surprise since this group was the oldest and most select group in the study.

Perhaps the most important result from the energy content questionnaire is that Cohort 1 students outscored Cohort 2, despite scoring no different from them on the energy unit 
TABLE 5

Grade Level Means on the Energy Content Questionnaire

\begin{tabular}{lcr}
\hline & Sample Size & Mean (SD) \\
\hline Cohort 2 & 77 & $9.4(2.5)$ \\
Cohort 1 & 55 & $10.3(2.1)$ \\
Chemistry & 35 & $8.6(1.8)$ \\
Physics & 29 & $11.2(2.3)$ \\
Total & 195 & $9.8(2.4)$ \\
\hline
\end{tabular}

TABLE 6

Contrasts Between Grade Levels on the Energy Content Questionnaire

\begin{tabular}{lcc}
\hline & $d f$ & $t$-Statistic \\
\hline Cohort 2 vs. Cohort 1 & 191 & $-2.39^{*}$ \\
Cohort 2 vs. chemistry & 191 & 1.63 \\
Cohort 2 vs. physics & 191 & $-3.86^{* * *}$ \\
Cohort 1 vs. chemistry & 191 & $3.49^{* * *}$ \\
Cohort 1 vs. physics & 191 & $-1.83 \sim$ \\
\hline
\end{tabular}

${ }^{* * *} p \leq .001 ;{ }^{* *} p \leq .01 ;{ }^{*} p \leq .05 ; \sim p \leq .1$.

posttest, $t(130)=0.978, p=\mathrm{NS})$, when they took the posttest at the end of their participation in the energy unit. These results suggest that, rather than forgetting what they learned about energy during the eighth grade, Cohort 1 students may have been better prepared for future energy-related learning in their biology class.

To test whether the difference between Cohort 1 and Cohort 2 scores on the energy content questionnaire was likely due to further energy learning during the ninth-grade biology course, we separated the energy content questionnaire into two subscores: one for items which were targeted to physical science benchmarks and one for items that were targeted to life science benchmarks. Since the energy unit dealt primarily with physical rather than biological phenomena, these subscores were useful in determining whether Cohort 1 students' higher score were likely a result of their learning in biology. We conducted one-way ANOVA with orthogonal contrasts to look for differences between grade levels on physical science items and life science items. The results are shown in Tables 7 and 8 .

\section{TABLE 7}

Grade-Level Means on Physical Science Items and Life Science Items From the Energy Content Questionnaire

\begin{tabular}{lccc}
\hline & & \multicolumn{2}{c}{ Mean $(S D)$} \\
\cline { 3 - 4 } & Sample Size & Physical Science Items & Life Science Items \\
\hline Eighth-grade science & 77 & $6.6(1.7)$ & $2.8(1.1)$ \\
Biology & 55 & $7.1(1.6)$ & $3.2(0.9)$ \\
Chemistry & 35 & $5.8(1.5)$ & $2.8(0.9)$ \\
Physics & 29 & $7.9(1.8)$ & $3.4(1.0)$ \\
Total & 195 & $6.8(1.8)$ & $3.0(1.0)$ \\
\hline
\end{tabular}




\section{TABLE 8}

\section{Contrasts Between Grade Levels on Physical Science Items and Life Science Items from the Energy Content Questionnaire}

\begin{tabular}{lccc}
\hline & & \multicolumn{2}{c}{$t$-Statistic } \\
\cline { 3 - 4 } & $d f$ & Physical Science Items & Life Science Items \\
\hline Cohort 2 vs. Cohort 1 & 191 & -1.65 & $-2.60^{*}$ \\
Cohort 2 vs. chemistry & 191 & $2.37^{*}$ & -0.320 \\
Cohort 2 vs. physics & 191 & $-3.46^{* * *}$ & $-2.74^{* *}$ \\
Cohort 1 vs. chemistry & 191 & $3.59^{* * *}$ & $2.11^{*}$ \\
Cohort 1 vs. physics & 191 & $-2.02^{*}$ & -0.749 \\
\hline
\end{tabular}

${ }^{* * *} p \leq .001 ;{ }^{* *} p \leq .01 ;{ }^{*} p \leq .05 ; \sim p \leq .1$.

While Cohort 1 students' scores on physical science items were not significantly higher than students in Cohort 2, their scores on life science items were significantly higher $(p \leq .05)$. Furthermore, Cohort 1 students significantly outscored chemistry students on physical science items $(p \leq .001)$ and on life science items $(p \leq .05)$. Despite taking virtually the same biology course as Cohort 1 students, 10th-grade chemistry students were outscored on energy-related life science items by the 9th-grade Cohort 1 students. These results suggest that students who had gone through the energy unit learned about energy in their biology course more successfully than students who went through virtually the same biology class but did not participate in the energy unit. That is, these results suggest that energy unit participants were better prepared for future energy-related learning.

To investigate whether the differences between Cohort 1, Cohort 2, and chemistry students were likely a result of PFL, we considered three alternative explanations for these results: (1) Cohort 1 students simply learned more about energy during their participation in the energy unit than students in Cohort 2, (2) the biology course contained a new emphasis on energy that had not been present before, and (3) Cohort 1 had a higher academic aptitude than other grade levels.

To test the first alternative explanation, we computed a one-way ANOVA to look for differences in Cohort 1 and Cohort 2 students' scores on the learning goals test. Table 9 shows these results.

While there was no significant difference between posttest scores in subsequent enactments, gain scores were significantly different and the difference in pretest scores approached significance. These differences were likely due to the fact that the eighth-grade

\section{TABLE 9}

\section{ANOVA Results Comparing Learning Goals Test Scores Between Cohorts 1} and 2

\begin{tabular}{lllllr}
\hline & \multicolumn{2}{c}{ Mean $(S D)$} & & \\
\cline { 2 - 3 } & Cohort 2 & Cohort 1 & & $d f$ & t-Statistic \\
\hline Learning goals pretest & $15.2(4.0)$ & $13.8(4.9)$ & & 129 & $1.81 \sim$ \\
Learning goals posttest & $27.0(4.9)$ & $27.8(4.8)$ & & 130 & -0.978 \\
Gain (posttest-pretest) & $11.7(4.8)$ & $14.0(5.8)$ & & 125 & $2.59^{*}$ \\
\hline
\end{tabular}

${ }^{* * *} p \leq .001 ;{ }^{* *} p \leq .01 ;{ }^{*} p \leq .05 ; \sim p \leq .1$. 
TABLE 10

Contrasts Between Grade Levels on Physical Science Items and Life Science Items From the Energy Content Questionnaire for Ninth-Grade Fairmeadows Students Who Were Not a Part of Cohort 1

\begin{tabular}{llccc}
\hline & & \multicolumn{3}{c}{$t$-Statistic } \\
\cline { 3 - 5 } & $d f$ & Physical Science Items & Life Science Items & Total Score \\
\hline Biology vs. chemistry & 44 & 1.12 & $-1.83 \sim$ & 0.110 \\
Biology vs. physics & 44 & -1.10 & -1.66 & -1.57 \\
\hline
\end{tabular}

${ }^{* * *} p \leq .001 ;{ }^{* *} p \leq .01 ;{ }^{*} p \leq .05 ; \sim p \leq .1$.

science teachers at Fairmeadows started to incorporate some of the ideas from the energy unit in the units that preceded it during the second enactment year. As a result, students' were likely to score better on the pretest and have lower gain scores. Most importantly, there were no detectable differences between posttest scores. This suggests that students' understanding of the learning goals at the end of the two subsequent enactments was not significantly different.

To test the second alternative explanation, we examined the energy content questionnaire results from students who were new to Fairmeadows in their ninth-grade year and thus not a part of Cohort 1. While we did not know what these students' energy-related learning opportunities were prior to their ninth-grade year, we could say for sure that they did not participate in the energy unit. If an increased emphasis on energy in the biology courserather than participation in the energy unit-was responsible for Cohort 1 students scoring higher than chemistry students, then we would expect to see the same effect for students who enrolled at Fairmeadows at the beginning of their ninth-grade year and were not a part of Cohort 1. The results of a one-way ANOVA with orthogonal contrasts comparing these biology, chemistry, and physics students are shown in Table 10.

Among this group of students, 9th graders did not outscore 10th graders on life science items. Along with the biology teacher's report that the content of her course had not changed, these results reinforce the claim that participation in the energy unit helped prepare students for future learning about energy.

Our third alternative explanation was that ninth graders simply had generally higher academic aptitude than students in other grade levels. Unfortunately, no large-scale assessment data were made available to us that enabled a fair comparison between grade levels. Although these data were not available, a comparison of pretest, posttest, and gain scores between Cohort 1 and Cohort 2 students do not support the assertion that Cohort 1 students were particularly better learners or had a higher aptitude than those in Cohort 2. Although we cannot eliminate this alternative explanation, it is unlikely that differences in aptitude confounded our results.

After considering alternative explanations, it remains that the most likely explanation of our observations is that the energy unit helps students develop an integrated understanding of energy that is organized around the principle of transformation, and that this more integrated understanding helps prepare students for future energy-related learning.

\section{DISCUSSION}

This study explores the effectiveness of an approach to middle school energy instruction that was designed according to the principles of learning-goals driven design (Krajcik et al., 
2008) and curricular coherence (Roseman et al., 2008; Shwartz et al., 2008) to address the core science concepts as specified in the BSL (AAAS, 1993) and NSES (NRC, 1996). This approach focuses on tracking energy transformations that occur in everyday, nonidealized systems that students are likely to experience outside of school. Results indicate that students who were taught using this approach developed a more integrated understanding of energy that was still held after 1 year and compared favorably with older students in the same school who had more energy-related instruction but learned about energy in a way that did not emphasize the central role of energy transformations in everyday phenomena. Furthermore, participation in the energy unit seemed to promote preparation for future energy-related learning. Although this study was not a direct comparison between various approaches to energy instruction, the discrepancies we observed between energy unit participants and nonparticipants shed light on the potential benefits of a coherent approach to middle school energy instruction that focuses on using energy transformation as a lens to make sense of everyday phenomena.

\section{Building Integrated Understandings}

During instruction, energy unit participants' conceptions of energy moved from a set of disconnected, and often incorrect, ideas toward an understanding in which their ideas were more accurate and better organized around the principle of transformation. This productive rearrangement of ideas helped them to apply their understanding to interpret a range of everyday scenarios - a hallmark of an integrated understanding (Duschl et al., 2007; Fortus \& Krajcik, in press; Linn \& Eylon, 2000; Roseman et al., 2008).

The energy unit promotes integrated understandings by grounding instruction within nonidealized phenomena that students are likely to encounter outside of school. In this way, the unit helps students develop their conceptions by building upon their intuitive ideas and everyday experiences rather than trying to replace their erroneous initial ideas with more correct ones (Smith et al., 1993). Equally important, the energy unit provides students with a set of conceptual tools (e.g., factors and indicators, energy transformation diagrams) that make it possible for them to interpret everyday phenomena and to predict/explain their behavior using the idea of energy transformation. By becoming more capable of reasoning about their world, students are more likely to apply what they have learned in their everyday lives both during and after instruction (Mualem \& Eylon, 2007).

\section{Quality Versus Quantity of Energy Learning Opportunities}

A key finding of this study is that energy unit participants' understanding was often better integrated than nonparticipants in the same school who were older, had more science courses, and were more self-selected for an interest in science. That is, simply having more learning experiences in science did not necessarily translate into a better integrated conception of energy. This result is in keeping with studies, which suggest that science instruction can often have little impact on students' conceptual understanding (Chi, 2005; Duit, 1984; Solomon, 1983). Although some 11th-grade physics students displayed wellintegrated conceptions, many 10th-grade chemistry and 11th-grade physics students had difficulty making sense of everyday scenarios from an energy perspective. On the other hand, energy unit participants in eighth and ninth grade were largely capable of using the idea of energy transformation to make sense of everyday scenarios. Overall, Fairmeadows students who participated in the energy unit were more capable of interpreting everyday phenomena using an energy perspective. 
Prior to the introduction of the energy unit, energy-related instruction in eighth grade did not focus on giving students tools to interpret everyday scenarios through the lens of energy transformation; rather, students studied energy through a more piecemeal approach that focused on one energy type at a time and on more idealized phenomena. By providing students with tools to reason from an energy perspective, the energy unit seems to have promoted students' development of a sophisticated conception of energy earlier than they otherwise might have. Our results suggest that participation in the energy unit both promoted development of a better integrated understanding of energy and helped prepare students for future learning in their subsequent high school biology course.

\section{Preparation for Future Learning}

Another key finding of this study is that students who participated in the energy unit during their eighth-grade year seemed better prepared than nonparticipants to learn about energy in their ninth-grade biology course. Despite taking virtually the same biology course, 10th-grade nonparticipants were outscored by 9th-grade participants when responding to energy-related life science content questions. To unpack why the energy unit seems to prepare students for future learning, it is useful to consider future learning as a form of learning transfer (Royer, Mestre, Dufresne, \& Mestre, 2005).

Bransford and Schwartz (1999) argued for the existence of a type of learning transfer that they called preparation for future learning (PFL). Unlike the notion that children can be generally prepared for "learning to learn" (Brown \& Kane, 1988), the PFL perspective refers to the relationship between learning in specific content areas and existing prior knowledge. While all children construct new knowledge based on their prior knowledge (Brooks \& Brooks, 1993; diSessa, 1993; von Glaserfeld, 1998; McCloskey, 1983), the PFL perspective is that the nature of students' prior knowledge determines their preparedness to learn successfully in knowledge-rich environments. With a more integrated understanding of energy, energy unit participants would have been well-positioned to learn how energy is involved in biological phenomena.

DiSessa and Wagner (2005) have presented a model to explain why integrated understandings promote learners' PFL. They describe learners' conceptual understandings as coordination classes (diSessa \& Sherin, 1998) of connected ideas, which function as lenses through which learners can view new information and situations in a way that is consistent with a particular concept. If learners possess an integrated understanding of a scientific concept, then they are capable of using this prior knowledge to discriminate new information, choose what is relevant, and understand the new context within the framework of their existing cognitive structure. DiSessa and Wagner (2005) note that naïve ideas often lack span (applicability in different contexts) and alignment (the ability to use information reliably across different contexts), whereas integrated understandings have more span and alignment, which makes them more useful for making sense of new information encountered in new situations.

Instruction can promote the span and alignment of students' ideas, and thus their PFL, by enabling them to activate their prior knowledge to reason in a variety of contexts (Bransford et al., 2000; Schwartz \& Bransford, 1998; Schwartz, Bransford, Sears, \& Mestre, 2005). By providing students with tools to use the idea of energy transformation to reason about a wide variety of everyday phenomena, the energy unit helped prepare students for future learning.

By focusing students' attention on the most central principles at work in everyday contexts, the energy unit did more than simply provide students with a set of prior knowledge to take into future learning environments, it promoted the type of prior knowledge that could 
help them navigate such information-rich environments and learn productively. This goes right to the heart of the idea that "less is more" in middle school science instruction.

\section{Implications}

Results from this study indicate that our approach to energy instruction had both an immediate effect of improving the integration of students' energy conceptions and a longterm effect of preparing students for future energy-related learning. These results refute the claims of other studies that students' acquisition of the energy concept is primarily mediated by maturational factors (Liu \& McKeough, 2005; Warren, 1986) and corroborate studies which assert that instruction plays a crucial role in students' concept acquisition (Duschl et al., 2007; Klahr \& Nigam, 2004; Linn et al., 2006; Smith et al., 2000; White \& Frederiksen, 1998).

We approached energy instruction with coherence (Roseman et al., 2008; Shwartz et al., 2008) in mind, that is, we developed the energy unit to focus students' attention on the most important ideas about energy and to dispense with unnecessary detail while investigating relevant phenomena. While many middle school energy curricula focus students' attention on performing simple calculations of energy quantities (e.g., work, kinetic energy, gravitational potential energy), such an emphasis necessarily limits the range of phenomena that students are equipped to understand and risks burying the central ideas of energy in the details of calculation. The set of factors and indicators utilized within the unit made it possible for middle school students to track energy transformations that occurred in everyday phenomena without becoming overwhelmed by the details of calculation. We do not intend to suggest that rigorous calculations of energy are unimportant; rather, such calculations are best left for later. This approach is aligned with the sequence described in the Atlas for Science Literacy, Volume 2, which recommends that middle school students focus qualitatively on energy transformation and high school students study its quantitative conservation.

The results of this study suggest that future middle school energy curricula may more effectively promote integrated understandings of energy if it is coherent and focuses students' attention on using the idea of energy transformation to interpret and explain everyday, nonidealized phenomena. Because energy is a central unifying idea in science, students with a more integrated understanding of energy are well positioned for future science learning.

\section{APPENDIX A: LEARNING GOALS OF THE ENERGY UNIT}

Learning Goal 1: There are different types of energy.

Learning Goal 2: All of what goes on in the universe involves some type of energy being transformed into another.

Learning Goal 3: Energy cannot be created or destroyed but changed from one type to another.

Learning Goal 4: Heat is almost always one of the products of energy transformation.

Learning Goal 5: There are multiple energy sources.

Learning Goal 6: Some energy sources are renewable; others are not.

Learning Goal 7: Human utilization of energy sources has various environmental and economic impacts. 


\section{APPENDIX B: ENERGY TYPES AND THEIR ASSOCIATED FACTORS AND INDICATORS}

\begin{tabular}{|c|c|c|}
\hline Energy Type & Factors & Indicators \\
\hline Kinetic energy & $\begin{array}{l}\text { Mass } \\
\text { Speed }\end{array}$ & Speed \\
\hline Light energy & Brightness $^{a}$ & Emission of light \\
\hline Sound energy & Loudness & Emission of sound \\
\hline Thermal energy & $\begin{array}{l}\text { Mass } \\
\text { Temperature } \\
\text { Type of substance }\end{array}$ & Temperature \\
\hline Chemical energy & $\begin{array}{l}\text { Type of substances } \\
\text { Mass }\end{array}$ & $\begin{array}{l}\text { Substances seeming } \\
\text { to appear or disappear }\end{array}$ \\
\hline Elastic energy & $\begin{array}{l}\text { Compression/elongation } \\
\text { Rigidity }\end{array}$ & $\begin{array}{l}\text { Compression or elongation } \\
\text { of an elastic substance }\end{array}$ \\
\hline Gravitational energy & Mass, height ${ }^{b}$ & Height \\
\hline Electrical energy & Voltage $^{c}$ & Complete circuit and a voltage source \\
\hline
\end{tabular}

${ }^{a}$ Although the energy of a single photon is dependent upon its wavelength, we wished to describe the light energy emitted by a macroscopic apparatus, which is better described by intensity.

${ }^{b}$ Acceleration of gravity was not included because it is assumed constant for all objects.

${ }^{c}$ Although voltage is a measure of electrical energy per charge, we believed that voltage alone was an adequate factor for electrical energy because in virtually all devices that use electrical energy, the charge-carrying particle is the electron.

We wish to thank Chris Gleason and Ann Novak, who provided essential and insightful feedback to our development team.

\section{REFERENCES}

American Association for the Advancement of Science. (1993). Benchmarks for science literacy. New York: Oxford University Press.

Ball, D. L., \& Cohen, D. K. (1996). Reform by the book: What is—or might be-the role of curriculum materials in teacher learning and instructional reform? Educational Researcher, 25(9), 6-8.

Biggs, A., Daniel, L., \& Feather, R. M. (2008). Glencoe science: Level red. New York: Glencoe/McGraw-Hill.

Bliss, J., \& Ogborn, J. (1985). Children's choices of uses of energy. European Journal of Science Education, 7(2), $195-203$.

Bransford, J. D., Brown, A. L., \& Cocking, R. R. (2000). How people learn: Brain, mind, experience, and school (expanded edition). Washington, DC: National Academies Press.

Bransford, J. D., \& Schwartz, D. L. (1999). Rethinking transfer: A simple proposal with multiple implications. Review of Research in Education, 24, 61-100.

Brooks, J. G., \& Brooks, M. G. (1993). In search for understanding: The case for constructivist classrooms. Alexandria, VA: Association for Supervision and Curriculum Development.

Brown, A. L., \& Kane, M. J. (1988). Preschool children can learn to transfer: Learning to learn and learning from example. Cognitive Psychology, 20, 493-523.

Brown, J. S., Collins, A., \& Duguid, P. (1989). Situated cognition and the culture of learning. Educational Researcher, 18(1), 32-41.

Bryce, T., \& MacMillan, K. (2009). Momentum and kinetic energy: Confusable concepts in secondary school physics. Journal of Research in Science Teaching, 46(7), 739-761.

Case, R. (1985). Intellectual development: Birth to adulthood. San Diego, CA: Academic Press.

Case, R. (1992). The mind's staircase: Exploring the conceptual underpinnings of children's thought and knowledge. Hillsdale, NJ: Erlbaum. 
Chi, M. T. H. (2005). Commonsense conceptions of emergent processes: Why some misconceptions are robust. Journal of the Learning Sciences, 14(2), 161-199.

Chi, M. T. H., Feltovich, P. J., \& Glaser, R. (1981). Categorization and representation of physics problems by experts and novices. Cognitive Science, 5, 121-152.

Chinn, C. A., \& Brewer, W. F. (1993). The role of anomalous data in knowledge acquisition: A theoretical framework and implications for science education. Review of Educational Research, 63(1), 1-49.

Clark, D. B. (2006). Longitudinal conceptual change in students' understanding of thermal equilibrium: An examination of the process of conceptual restructuring. Journal of the Learning Sciences, 24(4), 467563.

Clement, J., Brown, D. E., \& Zeitsman, A. (1989). Not all preconceptions are misconceptions: Finding "anchoring conceptions" for grounding instruction on students' intuitions. International Journal of Science Education, 11, $554-565$.

Cognition and Technology Group at Vanderbilt. (1992). The Jasper Series as an example of anchored instruction: Theory, program description, and assessment data. Educational Psychologist, 27, 291-315.

Davis, E. A. (2003). Prompting middle school science students for productive reflection: Generic and directed prompts. Journal of the Learning Sciences, 12(1), 91-142.

DeBoer, G., Dubois, N., Hermann Abell, C., \& Lennon, K. (2008). Assessment linked to middle school science learning goals: Using pilot testing in item development. Paper presented at the National Association of Research in Science Teaching Annual Conference, Baltimore, MD.

DeBoer, G., Hermann Abell, C., Gogos, A., Michiels, A., Reagan, T., \& Wilson, P. (2008). Assessment linked to science learning goals: probing student thinking through assessment. In J. Boaler, R. Douglas, \& C. Stearns (Eds.), Assessing science learning: Perspectives from research and practice. Washington, DC: National Science Teachers Association Press.

DiSessa, A. (1993). Toward an epistemology of physics. Cognition and Instruction, 12(2-3), 105-225.

DiSessa, A. (2000). Changing minds: Computers, learning, and literacy. Cambridge, MA: MIT Press.

DiSessa, A., \& Sherin, B. (1998). What changes in conceptual change? International Journal of Science Education, 20(10), 1155-1191.

DiSessa, A., Wagner, J. F., \& Mestre, J. P. (2005). What coordination has to say about transfer. In Transfer of learning (from a multidisciplinary perspective) (pp. 121-154). Greenwich, CT: Information Age.

DiSpezio, M., Linner-Leube, M., Lisowski, M., Skoog, G., \& Sparks, B. (1997). Science insights: Exploring matter and energy. Menlo Park, CA: Addison-Wesley.

Domenéch, J. L., Gil-Pérez, D., Gras-Martí, A., Guisasola, J., Martínez- Torregrosa, J., Salinas, J., Trumper, R., et al. (2007). Teaching of energy issues: A debate proposal for a global reorientation. Science \& Education, 16 , 43-64.

Driver, R., Squires, A., Rushworth, P., \& Wood-Robinson, V. (1994a). Making sense of secondary science: Research into children's ideas. New York: Routledge.

Driver, R., Squires, A., Rushworth, P., \& Wood-Robinson, V. (1994b). Making sense of secondary science: Supporting materials for teachers. London: Routledge.

Duit, R. (1984). Learning the energy concept in school \& empirical results from The Philippines and West Germany. Physics Education, 19, 59-66.

Duschl, R. A., Schweingruber, H. A., \& Shouse, A. W. (2007). Taking science to school: Learning and teaching science in grades K-8. Washington, DC: National Academies Press.

Feynman, R. P., Leighton, R. B., \& Sands, M. L. (1989). The Feynman lectures on physics (Vol. 1). Redwood City, CA: Addison-Wesley.

Flavell, J. (1994). Cognitive development: Past, present, and future. In R. Park, P. Ross, J. Ornstein, \& C. Zahn-Waxler (Eds.), A century of developmental psychology (pp. 569-587). Washington, DC: American Psychological Association.

Fortus, D., Dershimer, C., Krajcik, J. S., Marx, R. W., \& Mamlok-Naaman, R. (2004). Design-based science and student learning. Journal of Research in Science Teaching, 41(10), 1081-1110.

Fortus, D., \& Krajcik, J. S. (in press). Curriculum coherence and learning progressions. In B. Fraser, K. Tobin, \& C. McRobbie (Eds.), The international handbook of research in science education (2nd ed.). Dordrecht, The Netherlands: Springer-Verlag.

Fortus, D., Krajcik, J. S., Nordine, J. C., Plummer, J., Rogat, A., \& Switzer, A. C. (2005). How can I use trash to power my stereo? Ann Arbor: University of Michigan Center for Highly Interactive Classrooms, Curricula, \& Computing in Education, NSF Center for Learning Technologies in Urban Schools.

Gilbert, J., \& Pope, M. (1986). Small group discussions about conceptions in science: A case study. Studies in Science Education, 10, 61-98.

Kesidou, S., \& Roseman, J. E. (2002). How well do middle school science programs measure up? Findings from project 2061's curriculum review. Journal of Research in Science Teaching, 39(6), 522-549. 
Klahr, D., \& Nigam, M. (2004). The equivalence of learning paths in early science instruction: Effects of direct instruction and discovery learning. Psychological Science, 15, 661-667.

Krajcik, J. S., McNeill, K. L., \& Reiser, B. J. (2008). Learning-goals-driven design model: Developing curriculum materials that align with national standards and incorporate project-based pedagogy. Science Education, 92 , 1-32.

Kruger, C. (1990). Some primary teachers' ideas about energy. Physics Education, 25, 86-91.

Kruger, C., Palacio, D., \& Summers, M. (1992). Survey of English primary teachers' conceptions of energy, force, and materials. Science Education, 76, 339-351.

Lee, H., \& Liu, O. L. (2010). Assessing learning progression of energy concepts across middle school grades: The knowledge integration perspective. Science Education, 94(4), 665-688.

Linn, M. C., \& Eylon, B. (2000). Knowledge integration and displaced volume. Journal of Science Education and Technology, 9(4), 287-310.

Linn, M. C., \& Eylon, B. (2006). Science education: Integrating views of learning and instruction. In Handbook of educational psychology (2nd ed). New York: Erlbaum.

Linn, M. C., Eylon, B. S., Davis, E. A. (2004). The knowledge integration perspective on learning. In Internet environments for science education (pp. 2-46). Mahwah, NJ: Erlbaum.

Linn, M. C., Lee, H., Tinker, R., Husic, F., \& Chiu, J. L. (2006). Teaching and assessing knowledge integration in science. Science, 313, 1049-1050.

Liu, X., \& McKeough, A. (2005). Developmental growth in students' concept of energy: Analysis of selected items from the TIMSS database. Journal of Research in Science Teaching, 42(5), 493-517.

McCloskey, M. (1983). Naive theories of motion. In D. Gentner \& A. Stevens (Eds.), Mental models (pp. 229-324). Hillsdale, NJ: Erlbaum.

Mualem, R., \& Eylon, B. (2007). Physics with a smile \& explaining phenomena with a qualitative problem-solving strategy. The Physics Teacher, 45(3), 158-163.

National Research Council. (1996). National Science Education Standards. National Academies Press.

Nussbaum, J., \& Novick, S. (1982). Alternative frameworks, conceptual conflict and accommodation: Toward a principled teaching strategy. Instructional Science, 11(3), 183-200.

Osborne, R. J., \& Gilbert, J. (1980). A technique for exploring students' views of the world. Physics Education, $15,376-379$.

Piaget, J., \& Inhelder, B. (1971). The psychology of the child. New York: Basic Books.

Pintó, R., Couso, D., \& Gutierrez, R. (2005). Using research on teachers' transformations of innovations to inform teacher education. The case of energy degradation. Science Education, 89, 38-55.

Roseman, J. E., Linn, M. C., \& Koppal, M. (2008). Characterizing curriculum coherence. In Y. Kali, J. E. Roseman, M. C. Linn, \& M. Koppal (Eds.), Designing coherent science education: Implications for curriculum, instruction, and policy. New York: Teachers College Press.

Royer, J. M., Mestre, J. P., Dufresne, R. J., \& Mestre, J. P. (2005). Framing the transfer problem. In Transfer of learning from a multidisciplinary perspective (pp. vii-xxiv). Greenwich, CT: Information Age.

Ruiz-Primo, M., Shavelson, R., Hamilton, L., \& Klein, S. (2002). On the evaluation of systemic science education reform: Searching for instructional sensitivity. Journal of Research in Science Teaching, 39(5), 369-393.

Schwartz, D. L., \& Bransford, J. D. (1998). A time for telling. Cognition and Instruction, 16(4), 475-522.

Schwartz, D. L., Bransford, J. D., Sears, D., \& Mestre, J. P. (2005). Efficiency and innovation in transfer (pp. 1-51). Greenwich, CT: Information Age.

Seastrom, M. M., Gruber, K. J., Henke, R., McGrath, D. J., \& Cohen, B. A. (2004). Qualifications of the public school teacher workforce: Prevalence of out-of-field teaching 1987-1988 to 1999-2000 (revised). Washington, DC: U.S. Department of Education.

Shwartz, Y., Weizman, A., Fortus, D., Krajcik, J. S., \& Reiser, B. J. (2008). The IQWST experience: Using coherence as a design principle for a middle school science curriculum. The Elementary School Journal, 109(2), 199-219.

Smith, C. L., Maclin, D., Houghton, C., \& Hennessey, M. G. (2000). Sixth-grade students' epistemologies of science: The impact of school science experiences on epistemological development \& cognition and instruction. Cognition and Instruction, 18(3), 349-422.

Smith, J. P., diSessa, A., \& Roschelle, J. (1993). Misconceptions reconceived: A constructivist analysis of knowledge in pieces. Journal of the Learning Sciences, 3(2), 115-163.

Solomon, J. (1983). Messy, contradictory, and obstinately persistent: A study of children's out-of-school ideas about energy. School Science Review, 65(231), 225-233.

Starr, M. L., Casella, F., Fortus, D., Krajcik, J., Nordine, J. C., Plummer, J., Rogat, A., et al. (2009). Project-based inquiry science: Energy. Armonk, NY: It's About Time.

Stepans, J. (2003). Targeting students' science misconceptions: Physical science concepts using the conceptual change model (Vol. 3). Riverview, FL: Idea Factory. 
Swackhamer, G. (2005). Cognitive resources for understanding energy. Retrieved November 3, 2010, from http:// modeling.la.asu.edu/modeling/CognitiveResources-Energy.pdf.

Swackhamer, G., \& Hestenes, D. (2003). An energy concept inventory. Retrieved November 3, 2010, from http:// modeling.asu.edu/modeling/00Madison.ppt.

Todd, R., Kilpatrick, M., Earvolino, A., Garcia, L. A., \& Zapanta, L. (2002). Holt science \& technology (grade 6). Austin, TX: Holt, Reinhart, and Winston.

Trumper, R. (1990). Being constructive: An alternative approach to the teaching of the energy concept \& part one. International Journal of Science Education, 12, 343-354.

Trumper, R. (1993). Children's energy concepts: A cross-age study. International Journal of Science Education, 15(2), 139-148.

Trumper, R. (1998). A longitudinal study of physics students' conceptions of energy in pre-service training for high school teachers. Journal of Science Education and Technology, 7(4), 311-317.

van Huis, C., \& van den Berg, E. (1993). Teaching energy: A systems approach. Physics Education, 28(3), $146-153$.

von Glaserfeld, E. (1998). Cognition, construction of knowledge, and teaching. In M. R. Matthews (Ed.), Constructivism in science education (pp. 11-30). Dordrecht, The Netherlands: Kluwer Academic.

Warren, J. (1982). The nature of energy. European Journal of Science Education, 4(3), 295-297.

Warren, J. (1986). At what age should energy be taught? Physics Education, 21, 154-156.

Watts, M. (1983). Some alternative views of energy. Physics Education, 18, 213-217.

Watts, M., \& Gilbert, J. (1983). Enigmas in school science: Students' conceptions for scientifically associated words. Research in Science \& Technical Education, 1(2), 161-171.

White, B. Y., \& Frederiksen, J. R. (1998). Inquiry, modeling, and metacognition: Making science accessible to all students. Cognition and Instruction, 16(1), 3-118.

Wu, H., Krajcik, J. S., \& Soloway, E. (2001). Promoting understanding of chemical representations: Students' use of a visualization tool in the classroom. Journal of Research in Science Teaching, 38(7), 821-842. 